\title{
Antibodies to a Common Outer Envelope Antigen of Treponema hyodysenteriae with Antibacterial Activity
}

\author{
By R. SELLWOOD, ${ }^{*}$ K. A. KENT, $\dagger$ M. R. BURROWS, R. J. LYSONS \\ AND A. P. BLAND \\ AFRC, Institute for Animal Health, Compton Laboratory, Compton, Newbury, \\ Berks RG16 ONN, UK
}

(Received 6 January 1989; revised 27 April 1989; accepted 28 April 1989)

\begin{abstract}
Outer envelopes of Treponema hyodysenteriae strains P18A and VS1 were prepared and characterized by SDS-PAGE. In Western blot analysis of eleven strains of $T$. hyodysenteriae and two intestinal non-pathogenic spirochaetes, polyclonal antiserum raised to the outer envelopes of strain P18A contained antibodies primarily to two polypeptides. A $45 \mathrm{kDa}$ polypeptide was present in only two strains of $T$. hyodysenteriae, P18A and MC52/80, whereas another antigen of $16 \mathrm{kDa}$ was common to all eleven strains of $T$. hyodysenteriae but was not present in the two nonpathogens. Immunogold labelling of whole organisms suggested that the $16 \mathrm{kDa}$ antigen was present on the surface of the spirochaetes. In in vitro tests the serum agglutinated and inhibited growth of only the $T$. hyodysenteriae strains, suggesting that antibodies to the $16 \mathrm{kDa}$ antigen were responsible for these activities. Serum from a gnotobiotic pig infected with $T$. hyodysenteriae strain P18A had antibodies to the $16 \mathrm{kDa}$ antigen alone and also possessed agglutinating and growth-inhibitory activities.
\end{abstract}

\section{INTRODUCTION}

The aetiological agent of swine dysentery is Treponema hyodysenteriae (Taylor \& Alexander, 1971; Harris et al., 1972). It is an intestinal spirochaete which colonizes the mucosa of the large intestine of the growing pig and together with other bacterial species (e.g. Fusobacterium and Bacteroides spp.) gives rise to mucohaemorrhagic diarrhoea (Harris et al., 1978; Lysons et al., 1978; Joens et al., 1981) leading to dehydration and occasionally death of the infected animal. Pigs that have been infected with virulent strains of $T$. hyodysenteriae and recover from the disease have been shown to be immune to further infection (Olson, 1974; Joens et al., 1979; Rees et al., 1989).

In a comparison of the antigens of a virulent strain of $T$. hyodysenteriae and a non-pathogenic intestinal spirochaete (Treponema innocens) numerous cross-reacting antigens were detected by Western blotting with sera from pigs with clinical disease and also with convalescent porcine sera (Joens \& Marquez, 1986). One antigen $(16 \mathrm{kDa})$ was specific to $T$. hyodysenteriae. In a study by Chatfield et al. (1988) three antigens unique to virulent strains of $T$. hyodysenteriae were identified using hyperimmune rabbit sera raised against $T$. hyodysenteriae and absorbed with the non-pathogenic $T$. innocens; but the cellular location of these antigens was not described. More recent investigations (Kent et al., 1989) have demonstrated an immune response to the axial filament polypeptides of $T$. hyodysenteriae using immunoblotting techniques with serum from a pig recovered from swine dysentery. However, antibacterial activity of hyperimmune pig serum raised against axial filaments could not be demonstrated.

\footnotetext{
† Present address: National Institute for Biological Standards and Control, Blanche Lane, South Mimms,
} Potters Bar, Herts EN6 3QG, UK. 
Surface-orientated antigens of the outer envelope of the spirochaete are probably encountered by the host early in infection and an immune response directed against these components may, in part, be responsible for immunity of pigs to swine dysentery. Although there is no direct evidence to support this hypothesis in swine dysentery, investigations of the immune response in humans to Treponema pallidum have revealed the presence of antibodies to highly antigenic polypeptides (Hanff et al., 1982; Baker-Zander et al., 1985) and one of $47 \mathrm{kDa}$ has been shown to reside in the outer envelope (Jones et al., 1984; Marchitto et al., 1984). An investigation with monoclonal antibodies to this surface-exposed antigen revealed that the antibodies were effective both in in vitro complement-dependent immobilization and in neutralization tests (Jones et al., 1984; Marchitto et al., 1986). Bailey et al. (1987) also demonstrated immobilization of $T$. pallidum with a monoclonal antibody to a surface-associated $44 \mathrm{kDa}$ polypeptide.

In studies of the spirochaete Borrelia burgdorferi, antibodies to outer envelope antigens have been detected in the sera and synovial fluid of patients with Lyme disease (Barbour et al., 1983a, 1985; Craft et al., 1986), and monoclonal antibodies have been raised to an outer membrane polypeptide of $31 \mathrm{kDa}$ (Barbour et al., 1983 b) and also against polypeptides described as the 34 $\mathrm{kDa}$ range of polypeptides (Barbour et al., 1984). Likewise, patients infected with Leptospira interrogans serovar hardjo had antibodies to surface-exposed antigens (Chapman et al., 1988). However, little information exists of the antibacterial activity attributable to these antibodies.

This study is concerned with identification of polypeptide antigens present in the outer envelope of $T$. hyodysenteriae which ( $a$ ) are specific to $T$. hyodysenteriae, $(b)$ are exposed on the surface of the spirochaete and $(c)$ may stimulate the production of antibodies that have antibacterial activity.

\section{METHODS}

Bacterial strains. Eight strains of T. hyodysenteriae representing the LPS serotypes described by Kent $e t$ al. (1989), two additional strains from the USA, B204 (serotype 2) and B234 (serotype 1), and JWPM (serotype 2; isolated in the Netherlands) were used in this study. Two non-pathogenic, intestinal spirochaetes, PWS/A and M1, were isolated from healthy pigs (Hudson et al., 1976; Lemcke \& Burrows, 1979). The spirochaetes were cultivated in trypticase soya broth supplemented with $5 \%(\mathrm{v} / \mathrm{v})$ rabbit serum (Lemcke et al., 1979) and grown in large volumes as described by Kent et al. (1988).

Preparation of outer envelopes. The outer envelopes of $T$. hyodysenteriae strains P18A and VS1 were prepared by a modification of the method of Johnson et al. (1973). A one-litre, $24 \mathrm{~h}$ culture of strain P18A was centrifuged at $6000 \mathrm{~g}$ at $20^{\circ} \mathrm{C}$ and the bacterial pellet was washed once with phosphate-buffered saline (PBS; $0 \cdot 17 \mathrm{M}-\mathrm{NaCl}$, $\left.3.35 \mathrm{~mm}-\mathrm{KCl}, 0.01 \mathrm{M}-\mathrm{Na}_{2} \mathrm{HPO}_{4}, 1.84 \mathrm{mM}-\mathrm{KH}_{2} \mathrm{PO}_{4}, \mathrm{pH} 7.2\right)$ and resuspended in $40 \mathrm{ml}$ of PBS. Sodium dodecyl sulphate (SDS) solution $(10 \%, \mathrm{w} / \mathrm{v})$ was added to give a final concentration of $0.005 \%(\mathrm{w} / \mathrm{v})$ and the suspension was incubated for $15 \mathrm{~min}$ at room temperature with occasional mixing. The suspension was then centrifuged at $20000 \mathrm{~g}$ for $30 \mathrm{~min}$ and the clear supernatant fluid was filtered through a $0.45 \mu \mathrm{m}$ pore size membrane filter (Millipore). The outer envelopes were reaggregated by dialysis against several changes of distilled water for $7 \mathrm{~d}$ at $4{ }^{\circ} \mathrm{C}$ and were collected by centrifugation at $90000 \mathrm{~g}$ for $1 \mathrm{~h}$ at $4{ }^{\circ} \mathrm{C}$. The pellets were resuspended in distilled water and stored at $-20^{\circ} \mathrm{C}$.

$S D S-P A G E$ and Western blotting. The method of Laemmli (1970) was used to separate polypeptides on $12.5 \%$ $(\mathrm{w} / \mathrm{v})$ polyacrylamide gels using a $3.5 \%(\mathrm{w} / \mathrm{v})$ stacking gel. Samples were dissolved in sample buffer consisting of $62.5 \mathrm{mM}$-Tris $/ \mathrm{HCl}, 2 \%(\mathrm{w} / \mathrm{v}) \mathrm{SDS}, 2 \%(\mathrm{v} / \mathrm{v}) 2$-mercaptoethanol and $1 \%(\mathrm{v} / \mathrm{v})$ glycerol at $100{ }^{\circ} \mathrm{C}$ for $5 \mathrm{~min}$. Gels were run for $18 \mathrm{~h}$ at a constant voltage of $35 \mathrm{~V}$ and were either stained with PAGE Blue 83 (BDH) or electrophoretically transferred at $70 \mathrm{~V}$ for $4 \mathrm{~h}$ to nitrocellulose (Schleicher and Schuell) by the method of Towbin $e t$ al. (1979).

The method used for probing nitrocellulose filters with serum antibody was that described by Kent et al. (1989). The filter was treated with $20 \%(\mathrm{v} / \mathrm{v})$ foetal calf serum (FCS) in $0.05 \mathrm{M}$-Tris-buffered saline, $\mathrm{pH} 8.0$ (TBS) for $1 \mathrm{~h}$ with gentle agitation. The FCS was replaced with hyperimmune antiserum diluted 1/100 or antiserum from infected gnotobiotic pigs diluted $1 / 10$ in TBS containing $20 \%$ FCS for $1 \mathrm{~h}$. The antiserum was removed and the filter was successively washed ( 15 min each step) in TBS, TBS containing $0.1 \%$ Nonidet-P40, and finally TBS. The filter was then placed in TBS/FCS containing $0.5 \mu \mathrm{Ci}(18.5 \mathrm{kBq})^{125}$ I-labelled Protein A (Amersham) for $1 \mathrm{~h}$, washed as above, dried and exposed with RX type X-ray film (Fuji) using enhancing screens at $-70{ }^{\circ} \mathrm{C}$ for $18-72 \mathrm{~h}$.

Antisera. Gnotobiotic pig antisera were raised against outer envelopes (serum B50) and axial filaments (serum C11) from T. hyodysenteriae strain P18A as described by Kent et al. (1989). Convalescent porcine serum (CPS) was obtained from a pig that had persistent swine dysentery. 
Two gnotobiotic pigs (67A and 67B) were orally dosed on two consecutive days with $50 \mathrm{ml}$ of broth cultures $\left(5 \times 10^{8}\right.$ live organisms $\left.\mathrm{ml}^{-1}\right)$ of $T$. hyodysenteriae strain P18A and sera were collected $21 \mathrm{~d}$ after infection.

Slide agglutination test. The slide agglutination test was that described by Burrows \& Lemcke (1981).

Growth inhibition test. Inhibition of the growth of $T$. hyodysenteriae by antisera was tested by the method of Lemcke \& Burrows (1979).

Electron microscopy. Preparations of the outer envelope was negatively stained with $2 \%(\mathrm{w} / \mathrm{v})$ ammonium molybdate on Formvar-coated copper grids. For ultra-thin sectioning, membrane pellets were fixed in $3 \%(\mathrm{w} / \mathrm{v})$ glutaraldehyde in $0.1 \mathrm{M}$-phosphate buffer and post-fixed in $1 \%(\mathrm{w} / \mathrm{v})$ osmium tetroxide. Washed pellets were further fixed in $1 \%(\mathrm{w} / \mathrm{v})$ uranyl acetate, dehydrated, transferred to propylene oxide and embedded in Araldite. Immunogold labelling was performed by first allowing a drop of the washed suspension of spirochaetes to dry on a Formvar-coated nickel grid. The grids were treated with dilutions of hyperimmune gnotobiotic pig antiserum for $30 \mathrm{~min}$. The grids were rinsed with PBS and treated with $10 \mathrm{~nm}$ Protein A-gold particles (Janssen) for $15 \mathrm{~min}$. The grids were rinsed and negatively stained with ammonium molybdate. All grids were viewed in a Philips EM300 electron microscope.

\section{RESULTS}

\section{Outer envelope preparation}

SDS treatment of cultures of $T$. hyodysenteriae produced low yields of outer envelopes that were free of contaminating axial filaments. An electron micrograph of negatively stained outer envelopes of strain P18A is shown in Fig. 1(a). Dialysis of the SDS-soluble fraction against distilled water gave preparations of outer envelope that were predominantly lipid bilayers. Transmission electron microscopy of ultrathin sections (Fig. 1b) confirmed the trilaminar structure of these outer envelopes. These preparations were used, without further purification, for the production of antiserum.

\section{SDS-PAGE and Western blotting}

SDS-PAGE analysis of the outer envelope preparations showed the presence of many bands (Fig. 2). Similar bands were observed in both P18A and VS1 except for a band at $16 \mathrm{kDa}$ that was present in the outer envelope preparation from strain VS1 (lane 2) but was apparently absent in the outer envelope of strain P18A (lane 1). Fig. 3 shows the Western blot analysis of all strains of porcine intestinal spirochaetes probed with outer envelope serum B50. The serum reacted strongly with two antigens of approximately $45 \mathrm{kDa}$ and $16 \mathrm{kDa}$ of the homologous strain P18A (lane 7), and strain MC52/80 reacted similarly (lane 4). The antiserum reacted only with the $16 \mathrm{kDa}$ antigen in all other strains of $T$. hyodysenteriae. Although similar amounts of each strain were applied to the gel the intensity of the reaction to the $16 \mathrm{kDa}$ antigen was variable. Strain VS1 (lane 5) reacted more strongly than any other strain, whereas P35/2 (lane 3), B169 (lane 8) and B234 (lane 13) reacted only weakly. The antiserum did not react with any polypeptides of the non-pathogenic spirochaetes (lanes 1 and 2). Very weak reactions were also observed with all thirteen strains to antigens in the range 30 to $45 \mathrm{kDa}$, which corresponded to the axial filament polypeptides. When axial filament polypeptides of eight strains of $T$. hyodysenteriae (Kent et al., 1989) were separated by electrophoresis and transferred to nitrocellulose the B50 serum detected these polypeptides only after extended exposure of the autoradiograph (data not shown).

Fig. 4 shows an immunoblot of strain P18A probed with CPS, B50, C11, 67A and 67B sera. The $16 \mathrm{kDa}$ antigen was recognized by all sera except the axial filament serum $\mathrm{C} 11$ (lane 3 ). The serum from 67B (lane 2) also reacted with the axial filament polypeptides AF2, 3 and 4 but the serum from $67 \mathrm{~A}$ only detected the $16 \mathrm{kDa}$ antigen (lane 1 ). When these pigs were dosed with P18A, shedding of the organism from pig 67A was not observed for all $21 \mathrm{~d}$ and the animal was clinically normal. In contrast, pig 67B excreted the organism for $10 \mathrm{~d}$ commencing $2 \mathrm{~d}$ after infection and had abundant clear mucus in the faeces during this period.

The $45 \mathrm{kDa}$ polypeptide common to strains P18A and MC52/80 that was detected by the B50 antiserum (lane 4) was of similar size to the largest polypeptide (AF1) of axial filaments of P18A detected by the $\mathrm{C} 11$ serum (lane 3 ). 

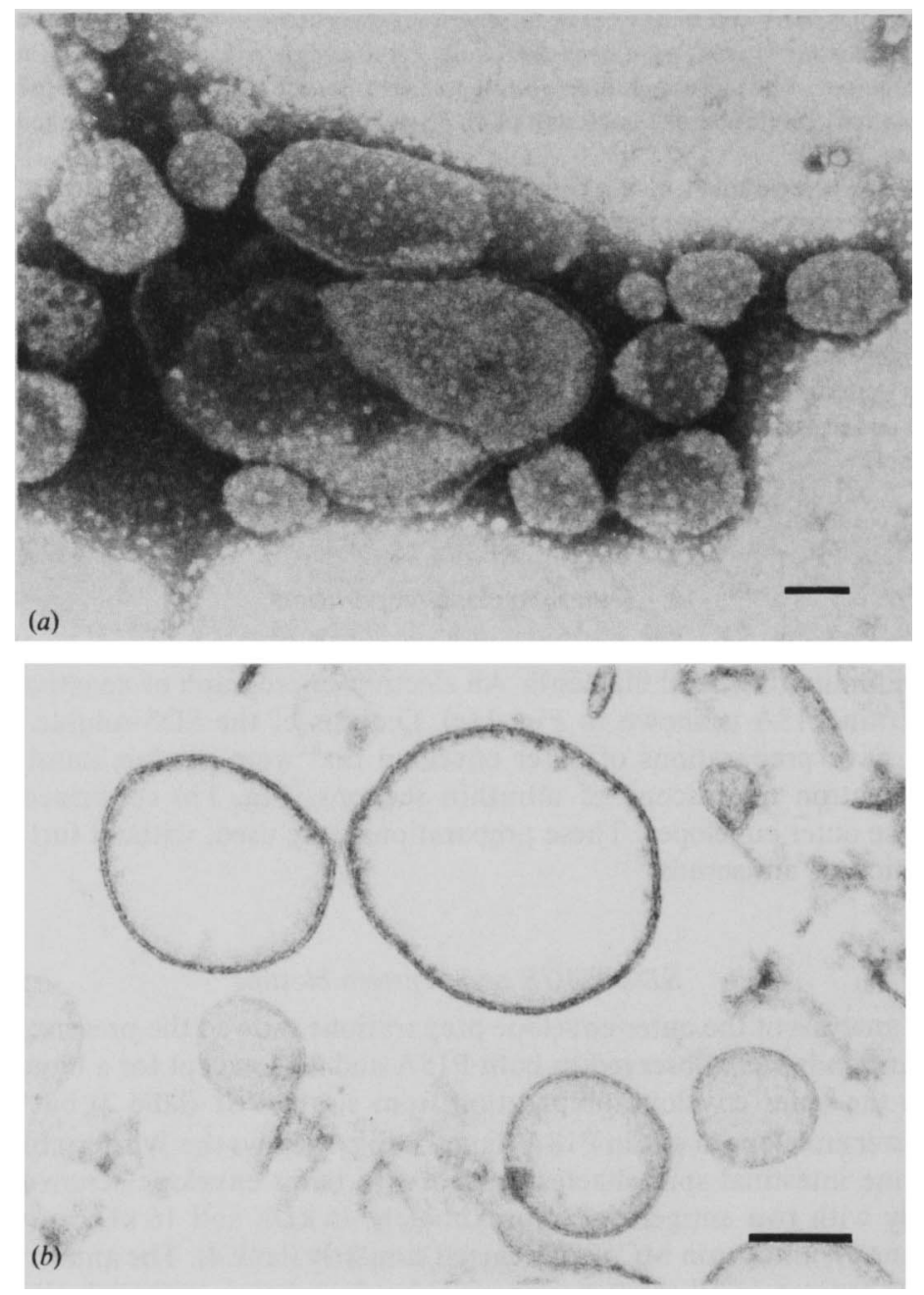

Fig. 1. Electron micrographs of outer envelopes of $T$. hyodysenteriae strain P18A. (a) Outer envelopes negatively stained with ammonium molybdate; $(b)$ ultrathin sections of outer envelopes stained with uranyl acetate. Bars $0 \cdot 1 \mu \mathrm{m}$.

\section{Immunogold labelling}

Surface labelling of the spirochaetes was apparent when strains P18A (Fig. 5a) and VS1 (Fig. $5 b$ ) were treated with B50 antiserum and Protein A-gold. The gold label appeared attached only to the outer envelope of both P18A and VS1; there was no apparent labelling of the axial filaments of either strain. Furthermore, there was also no labelling of the non-pathogenic strains M1 and PWS/A (Fig. 5c).

\section{Slide agglutination and growth inhibition tests}

Hyperimmune serum B50 agglutinated all $T$. hyodysenteriae strains and also the non-pathogen M1. However, when B50 was absorbed with both M1 and PWS/A, only strains of $T$. hyodysenteriae were agglutinated. The degree of agglutination observed was variable and several strains (P35/2, MC52/80 and B169) agglutinated only weakly. Antiserum 67A also agglutinated the $T$. hyodysenteriae strains but not the non-pathogens. 


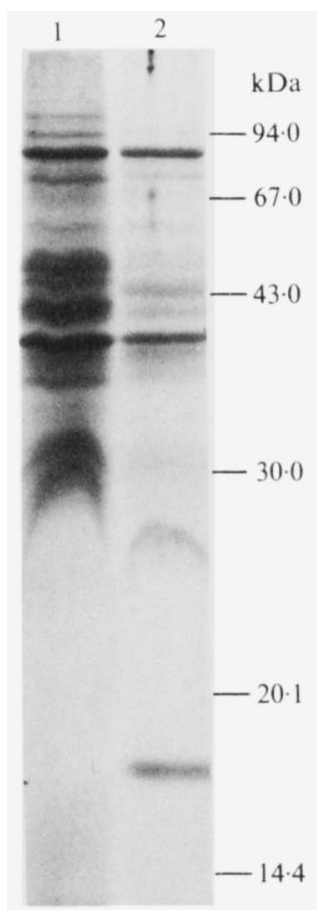

Fig. 2

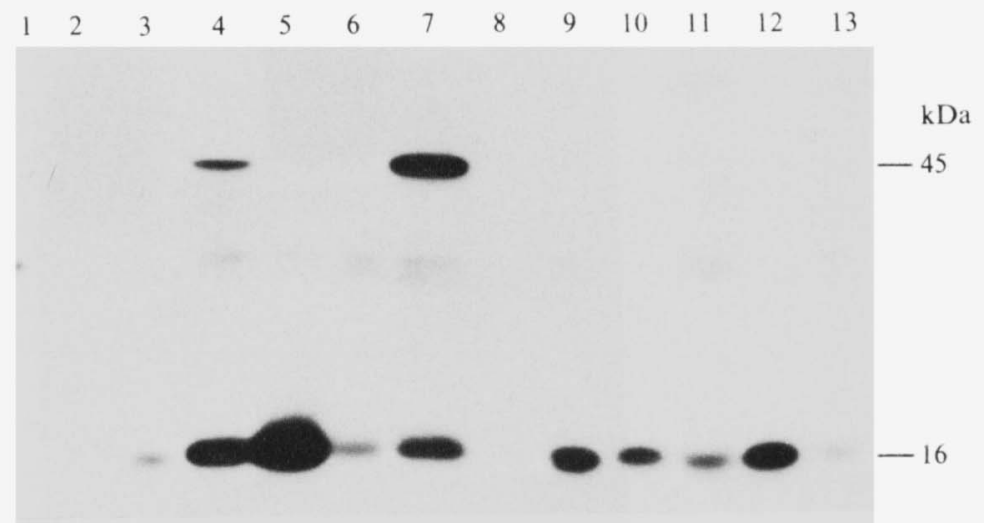

Fig. 3

Fig. 2. Outer envelopes of T. hyodysenteriae strains P18A (lane 1) and VSI (lane 2) separated by SDSPAGE and stained with PAGE Blue 83 .

Fig. 3. Western blots of whole cells from 11 strains of $T$. hyodysenteriae (lanes 3-13) and two nonpathogenic intestinal spirochaetes (lanes 1 and 2). Polypeptides were separated on a $12.5 \%$ SDS-PAGE gel, transferred to nitrocellulose and probed with hyperimmune gnotobiotic pig serum (B50). Lane 1, M1; lane 2, PWS/A; lane 3, P35/2; lane 4, MC52/80; lane 5, VS1; lane 6, KF9; lane 7, P18A; lane 8, B169; lane 9, JWPM; lane 10, S75/1; lane 11, B204; lane 12, B78; lane 13, B234.

Table 1. Growth inhibition tests on strains of T. hyodysenteriae using (a) hyperimmune gnotobiotic pig serum $(B 50)$ raised against outer envelopes of $T$. hyodysenteriae strain P18A and $(b)$ serum $(67 \mathrm{~A})$ from a gnotobiotic pig orally dosed with P18A

\begin{tabular}{|c|c|c|c|c|c|}
\hline \multirow[b]{2}{*}{ Strain } & \multicolumn{2}{|c|}{$\begin{array}{l}\text { Growth } \\
\text { inhibition } \\
\text { test* }\end{array}$} & \multirow[b]{2}{*}{ Strain } & \multicolumn{2}{|c|}{$\begin{array}{l}\text { Growth } \\
\text { inhibition } \\
\text { test }^{*}\end{array}$} \\
\hline & (a) & (b) & & (a) & (b) \\
\hline M1 & 0.0 & 0.0 & B169 & 1.5 & 0.0 \\
\hline PWS/A & 0.0 & 0.0 & JWPM & $3 \cdot 3$ & $3 \cdot 3$ \\
\hline P35/2 & NT & NT & S75/1 & 5.8 & $2 \cdot 5$ \\
\hline MC52/80 & 4.8 & $5 \cdot 0$ & B204 & $2 \cdot 8$ & $2 \cdot 0$ \\
\hline VS1 & 3.0 & 9.0 & B78 & $2 \cdot 3$ & $2 \cdot 0$ \\
\hline KF9 & $3 \cdot 3$ & $1 \cdot 3$ & B234 & $1 \cdot 0$ & $2 \cdot 0$ \\
\hline P18A & $7 \cdot 0$ & 3.0 & & & \\
\hline
\end{tabular}

NT, Not tested.

* Inhibition of growth is the distance ( $\mathrm{mm}$ ) from the disc to the edge of the clear zone (mean of two results).

Table 1 shows the results of growth inhibition tests using B50 and 67A sera. There was no inhibition of growth of the non-pathogens $\mathrm{Ml}$ and PWS/A but there was a marked inhibition of growth of all the $T$. hyodysenteriae strains tested except B169, which was not inhibited by $67 \mathrm{~A}$. Strain P35/2 did not grow on the medium used in the assay and was not tested. 


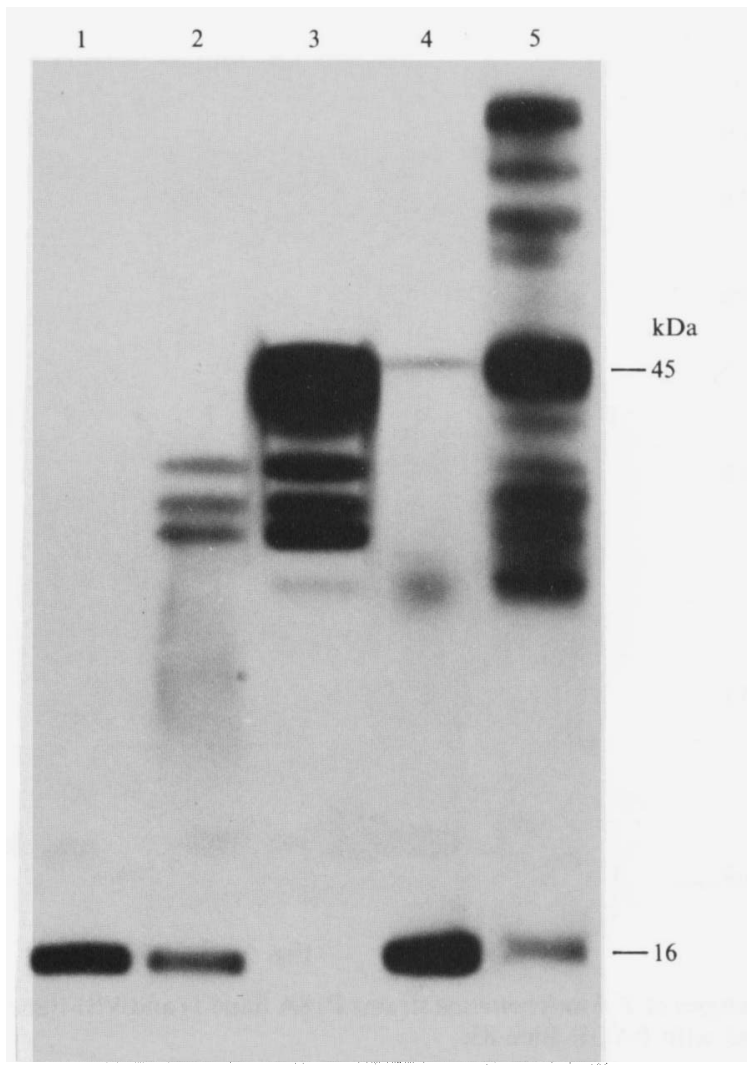

Fig. 4. Western blot of polypeptides of $T$. hyodysenteriae strain P18A, separated on a $12.5 \%$ SDSPAGE gel and probed with: serum from gnotobiotic pigs 67A (lane 1) and 67B (lane 2) infected with strain P18A; hyperimmune gnotobiotic pig serum (C11) raised against axial filaments (lane 3) or (B50) raised against outer envelopes (lane 4); and a convalescent pig serum (CPS) (lane 5).

\section{DISCUSSION}

Preparation of outer envelopes using a low concentration of SDS and dialysis against distilled water was used in order that trilaminar membranes could be seen by electron microscopy since dialysis against $\mathrm{Mg}^{2+}$ at concentrations greater than $5 \mathrm{~mm}$ produces aggregates which are devoid of trilaminar structures (Johnson et al., 1973). Mild treatment with $0.005 \%$ SDS produced outer envelopes with minimal contamination from axial filaments as judged by electron microscopy. Immunoblots of purified axial filaments versus the hyperimmune gnotobiotic porcine serum (B50) demonstrated that the preparation of outer envelopes was not completely devoid of axial filaments. However, contamination of outer envelopes with axial filaments can easily be monitored with polyclonal antibodies that are specific to axial filaments (Kent et al., 1989).

Studies of the polypeptides of outer envelopes of spirochaetes have in general been difficult, particularly with the non-cultivable spirochaete $T$. pallidum. Outer envelope polypeptides have been the subject of many investigations but such studies have, in addition, often identified axial filament and other periplasmic polypeptides (Stamm et al., 1987). However, the most conclusive evidence for the presence of surface-orientated polypeptides has come from the use of monoclonal antibodies to $T$. pallidum (Jones et al., 1984; Marchitto et al., 1984, 1986; Bailey et al., 1987). Similar studies have also been made with Leptospira interrogans (Jost et al., 1988) and Borrelia burgdorferi (Barbour et al., 1983b, 1984). T. hyodysenteriae is relatively easy to culture and prepare the outer envelope. 

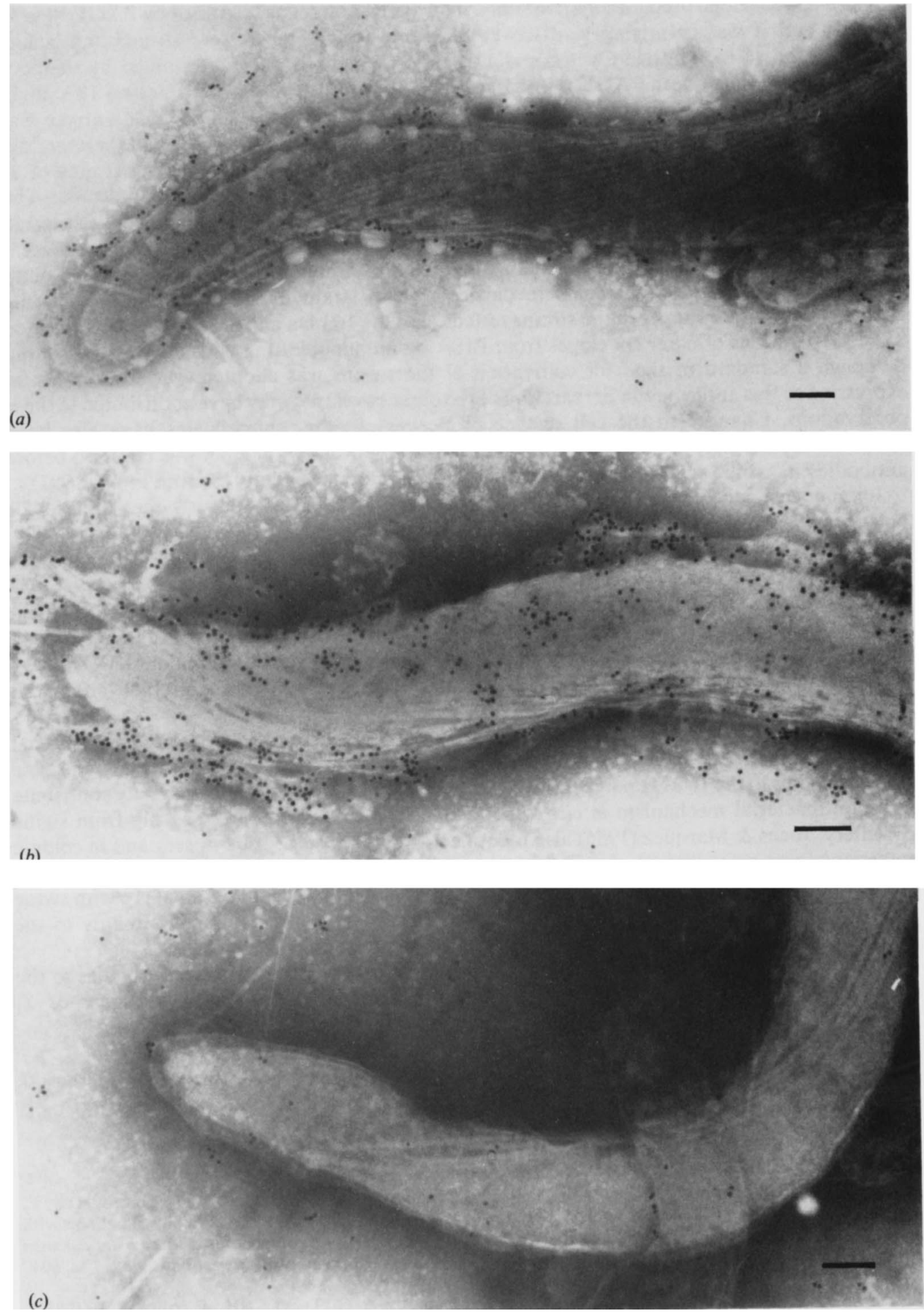

Fig. 5. Immunogold labelling of whole organisms of T. hyodysenteriae strains P18A (a) and VS1 (b), and of the non-pathogenic intestinal spirochaete PWS/A (c), using hyperimmune gnotobiotic pig serum B50. Bars, $0 \cdot 1 \mu \mathrm{m}$. 
The outer envelope preparations contained many polypeptides as identified by PAGE Blue 83 staining and it was surprising to discover that only two of these were strongly antigenic. Although the $16 \mathrm{kDa}$ antigen was apparently in low abundance (as determined by the poor sensitivity of staining with PAGE Blue 83) in outer envelope preparations of strain P18A, hightitre antiserum was obtained, suggesting that it is highly antigenic. The $45 \mathrm{kDa}$ antigen was common to two strains only (P18A and MC52/80) of different LPS serotypes and therefore did not show strain or serotype specificity. The $16 \mathrm{kDa}$ antigen was present in all strains of $T$. hyodysenteriae but not the non-pathogens and is therefore probably species specific. The variation in the concentration of this antigen in each strain could not be explained by the small differences in the amount of material applied to the gel. Either the $16 \mathrm{kDa}$ antigen was present in different amounts in the outer envelope of each strain or the serum (raised against outer envelopes of P18A) reacted weakly in particular with strain B169, suggesting only partial conservation of the epitopes in the strains tested. Also the $16 \mathrm{kDa}$ antigen could not be detected in all preparations of outer envelopes from P18A by immunoblotting with the B50 antiserum. Although a standard method for cultivation of the strains was adopted, variation either in expression of this antigen or in preparation of the outer envelopes may have contributed to these observations. Changes in the cell surface properties of other spirochaetes have also been observed; for example in vitro incubation of $T$. pallidum for more than $8 \mathrm{~h}$ was required before antibodies in rabbit syphilitic sera recognized three protein antigens (Stamm et al., 1987).

Immunogold labelling of the surface of strains P18A and VS1 suggests that the $16 \mathrm{kDa}$ polypeptide is a surface antigen because the $45 \mathrm{kDa}$ antigen, also detected by B50 serum in P18A, was not present in VS1. This conclusion is supported by the agglutination of all the strains by B50 serum and also $67 \mathrm{~A}$, a serum which had antibodies only to the $16 \mathrm{kDa}$ polypeptide. Although the $45 \mathrm{kDa}$ polypeptide migrated in SDS-PAGE close to the largest axial filament polypeptide it is probably an outer envelope polypeptide because of its presence in only two of the strains. Additional support for this conclusion is provided by the investigations of Kent et al. (1989), which demonstrated that the axial filament polypeptides were conserved among all strains of $T$. hyodysenteriae.

Inhibition of growth of strains of $T$. hyodysenteriae by B50 and 67A sera also suggests that antibodies to the $16 \mathrm{kDa}$ polypeptide are responsible for this activity. These results demonstrate that antibodies to the $16 \mathrm{kDa}$ polypeptide have in vitro antibacterial activity and may contribute to an antibacterial mechanism in vivo which could lead to protection of the pig from swine dysentery. Joens \& Marquez (1986) also identified a $16 \mathrm{kDa}$ polypeptide in sera and in colonic secretions from convalescent pigs and suggested that it might be important in stimulating a protective immune response. In the investigations presented here a conventional pig with swine dysentery and two gnotobiotic pigs challenged with strain P18A responded strongly to the $16 \mathrm{kDa}$ polypeptide, which indicates that it is also expressed in vivo.

Protection against swine dysentery may therefore be achieved, in part, by antibodies to the polypeptide described above. However, greater knowledge of the surface antigens of $T$. hyodysenteriae is necessary before the mechanisms of immunity can be understood.

The authors wish to thank Mr D. Hawkins for the photography. The technical assistance of Miss M. Desport, Miss R. Hill and Miss A. Clough is also gratefully acknowledged.

\section{REFERENCES}

Bailey, M. J., Cockayne, A. \& Penn, C. W. (1987). Monoclonal antibodies directed against surfaceassociated polypeptides of Treponema pallidum define a biologically active antigen. Journal of General Microbiology 133, 1793-1803.

BAKer-ZANDER, S. A., HoOK, E. W., Bonin, P., HaNDSField, H. H. \& LukehaRT, S. A. (1985). Antigens of Treponema pallidum recognised by IgG and IgM antibodies during syphilis in humans. Journal of Infectious Diseases 151, 264-272.
Barbour, A. G., Burgdorfer, W., Grunwaldt, E. \& STEERE, A. C. (1983a). Antibodies of patients with Lyme disease to components of the Ixodes dammini spirochaete. Journal of Clinical Investigation 72, 504515.

Barbour, A. G., Tessier, S. L. \& Todd, W. J. (1983b). Lyme disease spirochaetes and Ixodid tick spirochaetes share a common surface antigenic determinant defined by a monoclonal antibody. Infection and Immunity 41, 795-804. 
Barbour, A. G., Tessier, S. L. \& Hayes, S. F. (1984). Variation in a major surface protein of Lyme disease spirochaetes. Infection and Immunity 45, 94-100.

Barbour, A. G., Heiland, R. A. \& Howe, T. R. (1985). Heterogeneity of major proteins in Lyme disease borreliae: a molecular analysis of North American and European isolates. Journal of Infectious Diseases 152, 478-484.

BurRows, M. R. \& LEMCKe, R. M. (1981). Identification of Treponema hyodysenteriae by a rapid slide agglutination test. Veterinary Record 108, 187-189.

Chapman, A. J., Adler, B. \& Faine, S. (1988). Antigens recognised by the human response to infection with Leptospira interrogans serovar hardjo. Journal of Medical Microbiology 25, 269-278.

Chatfield, S. N., Fernie, D. S., Penn, C. W. \& DougAN, G. (1988). Identification of the major antigens of Treponema hyodysenteriae and comparison with those of Treponema innocens. Infection and Immunity 56, 1070-1075.

Craft, J. E., Fischer, D. K., Shimamoto, G. T. \& STEERE, A. C. (1986). Antigens of Borrelia burgdorferi recognised during Lyme disease. Appearance of a new immunoglobulin $\mathbf{M}$ response and expansion of the late immunoglobulin $\mathrm{G}$ response late in illness. Journal of Clinical Investigation 78, 934-939.

Hanff, P. A., Fehniger, T. E., Miller, J. N. \& LOVETT, M. A. (1982). Humoral immune response in human syphilis to polypeptides of Treponema pallidum. Journal of Immunology 129, 1287-1291.

Harris, D. L., Glock, R. D., Christensen, C. R. \& KINYON, J. M. (1972). Swine dysentery. I. Inoculation of pigs with Treponema hyodysenteriae (new species) and reproduction of the disease. Veterinary Medicine and Small Animal Clinician 67, 61-64.

Harris, D. L., AleXander, T. J. L., Whipp, S. C., Robinson, I. M., Glock, R. D. \& MatThews, P. J. (1978). Swine dysentery: studies of gnotobiotic pigs inoculated with Treponema hyodysenteriae, Bacteroides vulgatus and Fusobacterium retrophorum. Journal of the American Veterinary Medical Association 172, 468-471.

Hudson, M. J., Alexander, T. J. L. \& Lysons, R. J. (1976). Diagnosis of swine dysentery: spirochaetes which may be confused with Treponema hyodysenteriae. Veterinary Record 99, 495-500.

Joens, L. A. \& Marquez, R. B. (1986). Molecular characterization of proteins from porcine spirochaetes. Infection and Immunity 54, 893-896.

Joens, L. A., Harris, D. L. \& Baum, D. H. (1979). Immunity to swine dysentery in recovered pigs. American Journal of Veterinary Research 40, 13521354.

Joens, L. A., Glock, R. D., Whipp, S. C., Robinson, I. M. \& HARRIS, D. L. (1981). Location of Treponema hyodysenteriae and synergistic anaerobic bacteria in colonic lesions of gnotobiotic pigs. Veterinary Microbiology 6, 67-77.

Johnson, R. C., Wachter, M. S. \& Ritzi, D. M. (1973). Treponeme outer cell envelope: solubilization and reaggregation. Infection and Immunity 7, 249-258.

Jones, S. A., Marchitto, K. S., Miller, J. N. \& Norgard, M. V. (1984). Monoclonal antibody with haemagglutination, immobilization and neutralization activities defines an immunodominant,
47,000 mol. wt., surface exposed immunogen of Treponema pallidum (Nichols). Journal of Experimental Medicine 160, 1404-1420.

JOST, B. H., ADLER, B. \& FAINE, S. (1988). Reaction of monoclonal antibodies with species specific determinants in Leptospira interrogans outer envelope. Journal of Medical Microbiology 27, 51-57.

Kent, K. A., Lemcke, R. M. \& Lysons, R. J. (1988). Production, purification and molecular weight determination of the haemolysin of Treponema hyodysenteriae. Journal of Medical Microbiology 27, 215-224.

Kent, K. A., Sellwood, R., Lemcke, R. M., Burrows, M. R. \& Lysons, R. J. (1989). Analysis of the axial filaments of Treponema hyodysenteriae by SDS-PAGE and immunoblotting. Journal of General Microbiology 135, 1625-1632.

LAEMMLI, U. K. (1970). Cleavage of structural proteins during assembly of the head of bacteriophage T4. Nature, London 227, 680-685.

LemCKe, R. M. \& Burrows, M. R. (1979). A disc growth-inhibition test for differentiating Treponema hyodysenteriae from other intestinal spirochaetes. Veterinary Record 104, 548-551.

LEMCKe, R. M., Bew, J., BurRows, M. R. \& LySONS, R. J. (1979). The growth of Treponema hyodysenteriae and other porcine intestinal spirochaetes in a liquid medium. Research in Veterinary Science 26, 315-319.

Lysons, R. J., Hall, G. A., Alexander, T. J. L., BEW, J. \& Bland, A. P. (1978). Aetiological agents and pathogenesis of swine dysentery. In Proceedings of the 5th International Pig Veterinary Society Congress, Zagreb, p. M1.

Marchitto, K. S., Jones, S. A., Schell, R. F., Holmans, P. L. \& Norgard, M. V. (1984). Monoclonal antibody analysis of specific antigenic similarities among pathogenic Treponema pallidum subspecies. Infection and Immunity 45, 660-666.

Marchitto, K. S., Selland-Grossling, C. K. \& NORGARD, M. V. (1986). Molecular specificities of monoclonal antibodies directed against virulent Treponema pallidum. Infection and Immunity 51, 168176.

OLSON, L. D. (1974). Clinical and pathological observations on the experimental passage of swine dysentery. Canadian Journal of Comparative Medicine 38, 7-13.

Rees, A. S., Lysons, R. J., Stokes, C. J. \& Bourne, F. J. (1989). Antibody production by the pig colon during infection with Treponema hyodysenteriae. Research in Veterinary Science (in the Press).

Stamm, L. V., Hodinka, R. L., Wyrick, P. B. \& BASFORD, P. J. (1987). Changes in the cell surface properties of Treponema pallidum that occur during in vitro incubation of freshly extracted organisms. Infection and Immunity 55, 2255-2261.

TAYLOR, D. J. \& AleXander, T. J. L. (1971). The production of dysentery in swine by feeding cultures containing a spirochaete. British Veterinary Journal 127, lviii-lxi.

Towbin, H., Staehelin, T. \& Gordon, J. (1979). Electrophoretic transfer of proteins from polyacrylamide gels to nitrocellulose sheets; procedure and some applications. Proceedings of the National Academy of Sciences of the United States of America 76, 4350-4354. 